\title{
Digital and Extradigital Glomus Tumors: A Clinicopathological Analysis
}

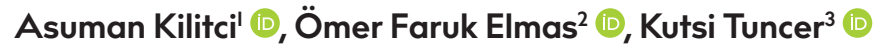 \\ 'Department of Pathology, Kırșehir Ahi Evran University School of Medicine, Kırșehir, Turkey \\ ${ }^{2}$ Department of Dermatology, Kırșehir Ahi Evran University School of Medicine, Kırșehir, Turkey \\ ${ }^{3}$ Department of Orthopaedics and Traumotology, Atatürk University School of Medicine, Erzurum, Turkey \\ ORCID iDs of the authors: A.K. 0000-0002-5489-2222; Ö.F.E. 0000-0002-5474-6508; K.T. 0000-0002-7544-2554.
}

Cite this article as: Kilitci A, Elmas ÖF, Tuncer K. Digital and Extradigital Glomus Tumors: A Clinicopathological Analysis. Cyprus J Med Sci 2020; 5(4): 323-6.

\section{BACKGROUND/AIMS}

Glomus tumors (GTs) refer to a rare group of perivascular tumors that usually affect the digital region. The lesions are histologically composed of vessels and glomus cells in varying proportions. The present study was designed to reveal the clinicopathological findings of the entity.

\section{MATERIAL and METHODS}

We reviewed the demographic, clinical, and histopathological features of the patients with GTs who were admitted to our tertiary center in the previous decade.

\section{RESULTS}

Total 16 patients were enrolled, including 9 men and 7 women. The mean patient age was $57.8 \mathrm{y}$. The most common location was the finger followed by other locations that included the chest wall (2), elbow $(I)$, forearm $(I)$, nose $(I)$, anterior abdominal wall $(I)$, hip $(I)$, back $(I)$, thigh $(I)$, knee (I), and foot (I). Seven patients presented with pain and localized tenderness. Subungual involvement was more common among women (4). All the lesions were solitary, soft in consistency, yellowish/brown in color, and regular in shape with smooth contours. The size of the lesions ranged from 0.5 to $2.5 \mathrm{~cm}$ (average size: $1.25 \mathrm{~cm}$ ). Histopathologically, the patients were classified into 3 main types, including solid type, glomangioma type, and glomangiomyoma type. Edematous and extensive myxoid stromal changes were found in 4 patients. Immunhistochemical study was performed to support the diagnosis in 8 patients. Ki- 67 expressions were "low" for all 8 specimens. All the patients were treated with total excision, and there was no recurrence in any case during at least l y of follow-up.

\section{CONCLUSION}

Extradigital GTs are more common than digital tumors. It should be kept in mind that a glomus tumor has the ability to involve different sites in the body. The differential diagnosis of painful and painless subcutaneous nodules in any location should include GTs.

Keywords: Glomus tumor, histopathology, digital, extradigital

\section{INTRODUCTION}

Glomus tumor (GT) describes a benign neoplastic proliferation that originates from the glomus body. Glomus bodies, also called neuromyo-arterial bodies, are involved in body temperature regulation and are most numerous in the fingers and toes (I). About $75 \%$ of GTs are located in the fingers and $65 \%$ of them are located in the subungual space in particular. Solitary GTs are typically painful, while multiple GT can be painless (2). Extradigital GTs can be small in size, asymptomatic, non-palpable, and painless (I-4). Owing to these subtle clinical features, the diagnosis of extradigital GT may be challenging. However, in cases of painful lesions, the pain can be considered as "idiopathic pain", and the patients may be referred to irrelevant departments, including rheumatology, neurology, and psychiatry; leading to the administration of inappropriate treatment regimens, such as cortisone injection, physiotherapy, and nerve decompression (5).

Histologically, a GT is composed of glomus cells, blood vessels, and smooth muscle cells in varying proportions. GTs are histologically classified into solid type, glomangioma, or glomangiomyoma as per the predominant histological component $(3,6)$. GTs rarely show malignant nature $(7)$. 
Few studies have investigated the clinical and histological characteristics of GTs, and most of these studies are single case reports and small case series. The present study aimed to contribute toward an understanding of the clinicopathological nature of the entity.

\section{MATERIAL and METHODS}

This retrospective study included a study of the clinical, demographic, and histopathological features of patients with a histopathological diagnosis of GT over a period of 10 y (January 2010 to January 2020). Hematoxylin Eosin (H反E) stained slides and the slides subjected to immunohistochemical staining were reviewed to confirm the diagnosis. Patients for whom insufficient clinical information was available were excluded. Descriptive statistical analyses were performed using the Statistical Package for Social Sciences Version 22.0 (IBM SPSS Corp.; Armonk, NY, USA) for Windows program. Informed consent was obtained from all participants. All the procedures were performed as per the principles in the Helsinki Declaration, and the study was approved by the local ethics committee (Decision date and number: 2020-02/20).

\section{RESULTS}

Total 16 patients, including 9 men and 7 women were enrolled. The mean patient age was $57.8 \mathrm{y}$. The most common localization was in the subungual area $(n=5)$ followed by that in the trunk $(n=3)$, elbow $(n=1)$, forearm $(n=1)$, nose $(n=1)$, gluteal region $(n=l)$, and back $(n=\mid)$. Most lesions $(n=\mid l)$ had an extradigital localization. The subungual involvement was more common in women $(n=4)$. The only symptom was pain that was present in 7 patients. The remaining 9 patients had cutaneous nodular growth (Figure I). All the patients

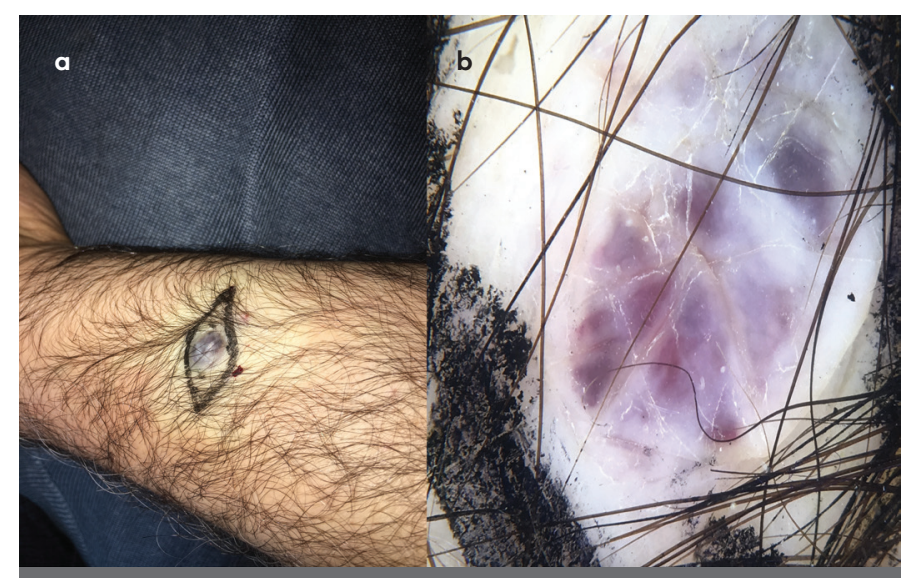

Figure I. a, b. (a) A painful purple nodule located on the extensor surface of the left arm (b) Dermoscopic examination of a glomus tumor. Large purple clods arranged in a jigsaw-like fashion on a white structureless background

\section{Main Points:}

- Glomus tumor has the ability to involve different sites in the body.

- The differential diagnosis of painful and painless subcutaneous nodules in any location should include glomus tumor.

- In addition to classical histological features, GTs may show secondary histological changes, including large myxoid areas, hyalinization, edema, and rarely, calcification. presented with a single lesion. The mean tumor diameter was 1.25 $\mathrm{cm}$ (diameter range: $0.5-2.5 \mathrm{~cm}$ ). Only digital specimens $(n=5)$ were submitted with a preliminary diagnosis of GT. None of the extradigital lesions had a preliminary diagnosis of GT. Total excision was the only treatment method used for all the included lesions.

Macroscopically, all the lesions were soft in consistency, yellowish/brown in color, and regular in shape with smooth contours. With respect to the histopathological features, $50 \%$ of the lesions $(n=8)$ were located in the lower dermis, while the other $50 \%$ were located in the subcutaneous tissue. The most common histopathological subtype was solid type ( $n=10,62.2 \%)$ followed by glomangioma $(n=5,31.3 \%)$, and glomangiomyoma $(n=1$, 6.2\%). All digital GTs were classified as solid type.

Seven lesions showed nerve fibers within or around the tumor, while the other lesions were free of the nerve fibers (Figure 2). Four lesions showed large myxoid edematous areas, while 2 showed hyaline
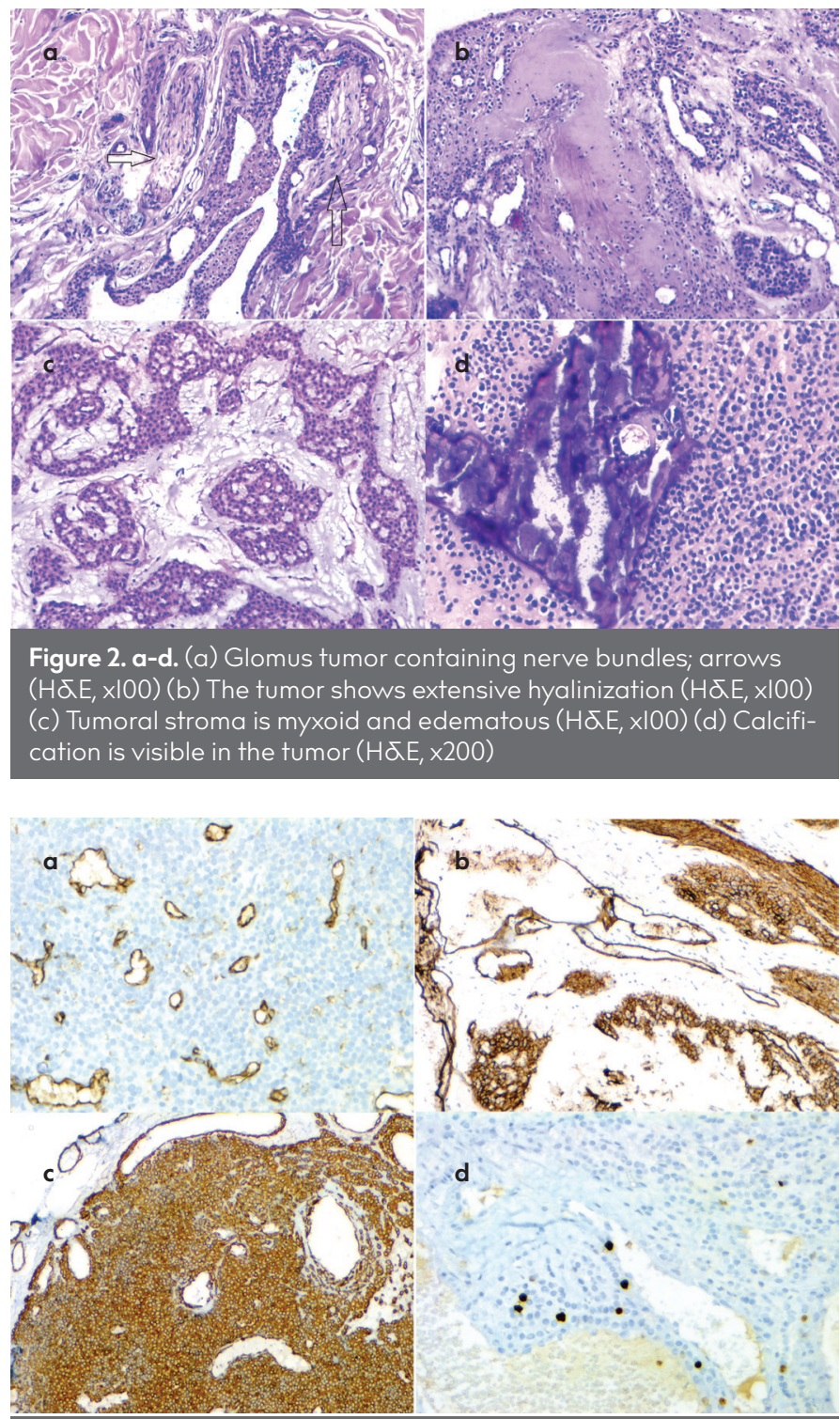

Figure 3. a-d. (a) Vessels staining with CD3I, negative glomus cells $(H \delta E, \times 200)(b, c)$ Glomus tumor reacts with CD34 and SMA (HסE, $\times 100 ; H \delta E, x 100)(d) K i-67$ proliferative index is very low in the glomus tumor $(H \delta E, \times 200)$ 


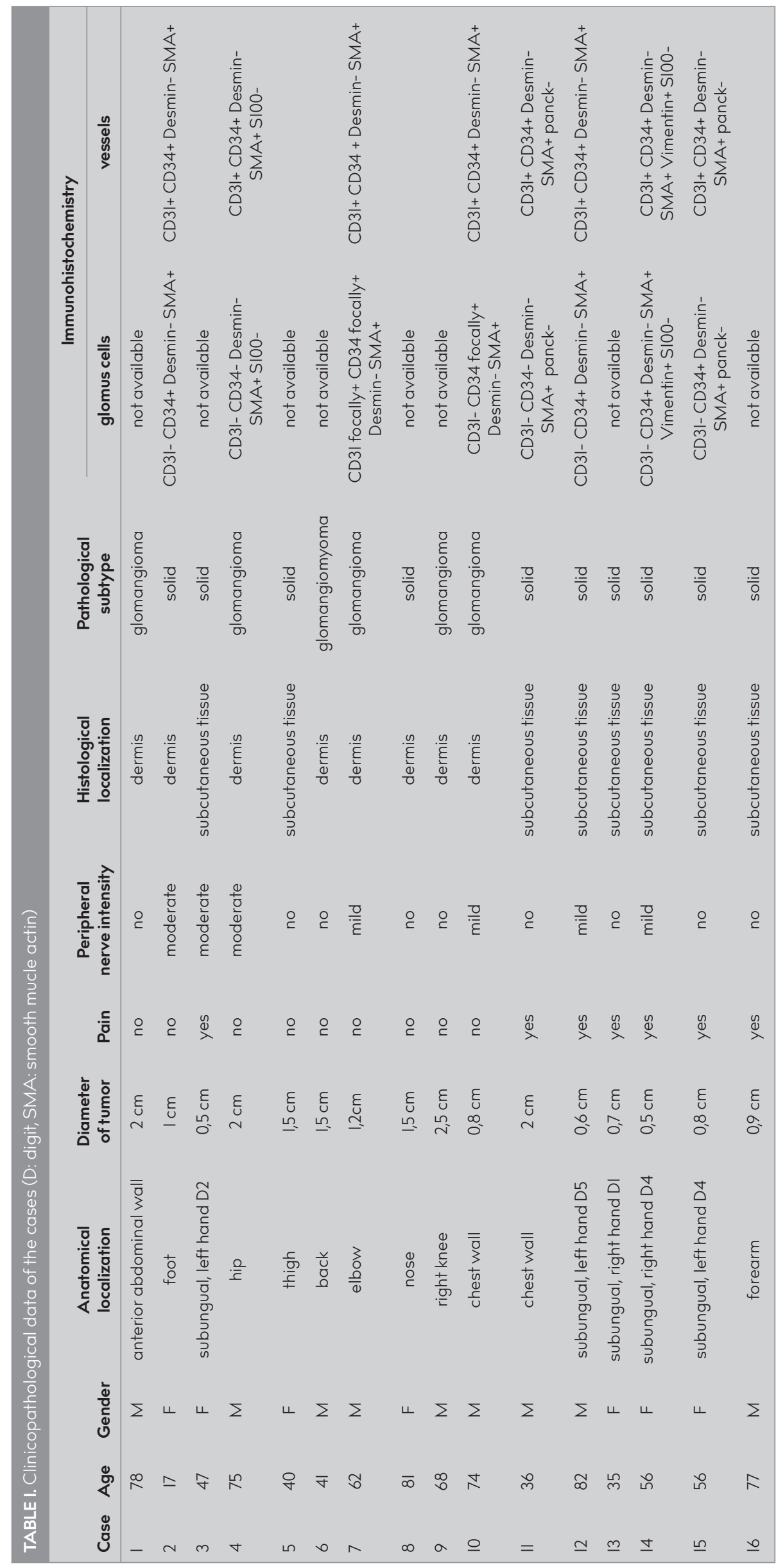

degeneration. Dystrophic calcification was evident in another lesion (Figure 2). None of the lesions showed nuclear atypia, pleomorphism, or mitosis. Total 8 (50\%) lesions were also evaluated using immunohistochemical stains to confirm the diagnosis (Figure 3). The demographic, clinical, histopathological, and immunohistochemical data of the patients are demonstrated in Table I.

\section{DISCUSSION}

The exact etiopathogenesis of GT is unknown; however, trauma and hereditary factors have been implicated. Some authors suggested that glomus bodies proliferate in response to trauma $(8,9)$. In a study, a history of trauma was present in $20 \%-30 \%$ of the patients diagnosed with GTs (I). In our study, none of the patients had a history of trauma.

Pain is a common symptom of GTs. The pathogenetic mechanism of pain in GT is clearly unknown; however, various hypotheses involving the sensitivity of the capsule to pressure; the release of chemical substances, such as histamine and heparin from the mast cells; substance P and TRPVI expression in glomus cells; and an increase in nerve fibers penetrating into the tumor have been proposed $(3,8)$. In the present study, 3 of the 7 patients who had a painful lesion histologically showed a mild to moderate number of peripheral nerve fibers in the tumor. It is noteworthy that 4 of the 9 patients without pain also demonstrated a low number of nerve fibers. The pain status does not appear to have a significant correlation with the presence or absence of peripheral nerve fibers.

Extradigital cases are usually painless, and typically, a cutaneous mass or discoloration is the main complaints $(I, 4)$. In keeping with the relevant literature, in our study, only 2 of the II patients with extradigital GTs had pain and localized tenderness, while all digital subungual lesions $(n=5)$ were tender and painful. The asymptomatic nature of the extradigital GTs poses a clinical diagnostic challenge. They are usually clinically misdiagnosed as nevus, melanoma, hemangioma, pyogenic granuloma, neuroma, leiomyoma, and spiradenoma (I, I0). In a study, only $20 \%$ of the extradigital tumors received a correct preliminary diagnosis by a clinician (3). In this study, none of the extradigital GTs was submitted with a preliminary diagnosis of GT.

In GTs, the size of the lesion is typically small and does not exceed $\mathrm{I} \mathrm{cm}$ in most patients (I, II). The lesions located in the lower extremi- 
ties can exceed $2 \mathrm{~cm}$ in diameter (I2). In this study, 8 lesions (50\%) were $<\mathrm{l} \mathrm{cm}$, while 7 lesions (44\%) had sizes ranging from $\mathrm{l} \mathrm{cm}$ to 2 $\mathrm{cm}$. Only one lesion was $>2 \mathrm{~cm}$. In our study, the mean tumor size was slightly larger than those reported in other studies $(I, I I, I 2)$.

Solid GTs are predominantly composed of glomus cells, while glomangiomas mainly include vascular structures. Glomangiomyomas are composed of fusiform smooth muscle cells $(3,10)$. In this study, the most common histopathological subtype was the solid type $(n=10$, $62.2 \%)$ followed by glomangioma ( $n=5,31.3 \%)$, and glomangiomyo$\mathrm{ma}(\mathrm{n}=1,6.2 \%)$. These rates were respectively reported as $73 \%, 19 \%$, and $8 \%$ by Einzinger and Weiss; as $76.5 \%, 23.5 \%$, and $0 \%$ by Kim SH et al.; and as $77.8 \%, 22 \%$, and $0 \%$ by Kim MG et al $(6,10,13)$.

The main differential diagnosis of solid GTs includes eccrine spiradenoma and hidradenoma that are characterized by focal ductal differentiation and positivity for epithelial markers unlike GT. Glomangioma and glomangiomyoma can be confused with hemangioma and leiomyoma wherein glomus cells distributed in the vessel wall are absent (14).

In suspected cases, immunohistochemical studies should be performed to avoid misdiagnosis. In GTs, the tumor cells are positive for smooth muscle actin (SMA) and rarely, focally positive for desmin. CD34 may also be positive. In this study, 8 (50\%) lesions were evalvated using immunohistochemical stains to confirm the diagnosis. In keeping with the relevant literature, SMA was positive for all the lesions, while desmin was negative. CD34 was positive in 6 lesions in varying degrees. Only one lesion showed positive CD3l staining.

GTs may exhibit secondary histological changes, including large myxoid areas, hyalinization, edema, and in some cases, calcification. In this study, 4 lesions showed large myxoid edematous areas, while two demonstrated hyaline degeneration. Calcification was evident in another lesion. Edema and myxoid changes were reported in $11.8 \%$ of the patients in a 17 -patient series performed by $\mathrm{Kim} \mathrm{SH}$ et al. and in $22.2 \%$ of the 27 tumors evaluated by Kim MG et al $(6,10)$. To prevent misdiagnosis, possible secondary changes in GTs should be considered carefully.

The overwhelming majority of GTs is benign; however, malignancy may be present rarely. The histological criteria for malignancy include a high mitotic count (5/50 HPF), a diameter $>2$ $\mathrm{cm}$, and the presence of necrosis and pleomorphism that were not observed in any of the included lesions (I5).

The single effective treatment method for GT is total excision (I). Inadequate excision is associated with early recurrence. Late recurrence may indicate multiple tumors that are initially overlooked. The reported recurrence rates range from $12 \%$ to $33 \%(\mathrm{l}$, $2,10)$. In the present study, all the excision specimens that were submitted had tumor-free margins, and none of the patients experienced recurrence during the l-year period of follow up.

Our study has certain limitations in terms of the retrospective nature and relatively small sample size. The reason for the small number of patients with a histopathological diagnosis of GT despite a period of 10 y may be the high number of asymptomatic patients who did not consult any department. The high number of patients who were clinically misdiagnosed or treated conservatively may be other causes.
In conclusion, considering these subtle clinical features, the diagnosis of extradigital GT may pose a diagnostic challenge. Thus, the differential diagnosis of painless and painful nodular growths should include GT in addition to other relevant preliminary diagnoses for the enhancement of a clinicopathological correlation that is key for the diagnosis of many cutaneous tumors.

Ethics Committee Approval: Ethics committee approval was received for this study from the ethics committee of Ahi Evran University Faculty of Medicine Clinical Research (2020-02/20).

Informed Consent: Informed consent was obtained from all participants.

Peer-review: Externally peer-reviewed.

Author contributions: Concept - A.K., Ö.F.E.; Design - A.K.; Supervision A.K., Ö.F.E.; Resource - Ö.F.E., K.T., A.K.; Materials - A.K.; Data Collection and/or Processing - Ö.F.E., A.K.; Analysis and/or Interpretation - K.T.; Literature Search - K.T.; Writing - A.K., Ö.F.E., K.T.; Critical Reviews - Ö.F.E.

Conflict of Interest: Authors have no conflicts of interest to declare.

Financial Disclosure: The authors declared that this study has received no financial support.

\section{REFERENCES}

I. Schiefer TK, Parker WL, Anakwenze OA, Amadio PC, Inwards CY, Spinner RJ. Extradigital glomus tumors: a 20-year experience. Mayo Clin Proc 2006; 8I(I0): 1337-44. [Crossref]

2. Santoshi JA, Kori VK, Khurana U. Glomus tumor of the fingertips: A frequently missed diagnosis. J Family Med Prim Care 2019; 8(3): 904-8. [Crossref]

3. Venugopal PR. Extradigital Glomus Tumor-a Rare Cause for Undiagnosed Chronic Pain in Unusal Sites. Indian J Surg 2015; 77(3): 9102. [Crossref]

4. Sbai MA, Benzarti S, Gharbi W, Khoffi W, Maalla R. Glomus tumor of the leg: a case report. Pan Afr Med J 2018; 31: 186. [Crossref]

5. Shin DK, Kim MS, Kim SW, Kim SH. A Painful glomus tumor on the pulp of the distal phalanx. J Korean Neurosurg Soc 2010; 48: 185-7. [Crossref]

6. Kim MG, Lee DY, Lee JH, Yang JM, Lee ES, Kim WS. A clinical and histopathologic analysis of 27 cases of glomus tumors. Korean $\mathrm{J}$ Dermatol 2006; 44(3): 267-73.

7. Beksaç K, Dogan L, Bozdogan N, Dilek G, Akgul GG, Ozaslan C. Extradigital Glomus Tumor of Thigh. Case Rep Surg 2015; 2015: 638283. [Crossref]

8. Morey VM, Garg B, Kotwal PP. Glomus tumours of the hand: review of literature. J Clin Orthop Trauma 2016; 7(4): 286-91. [Crossref]

9. Samaniego E, Crespo A, Sanz A. Key diagnostic features and treatment of subungual glomus tumor. Actas Dermosifiliogr (English Edition) 2009; 100(I0): 875-82. [Crossref]

10. Kim SH, Suh HS, Choi JH, Sung KJ, Moon KC, Koh JK. Glomus tumor: a clinical and histopathologic analysis of 17 cases. Ann Dermatol 2000; 12(2): 95-I0I. [Crossref]

II. Moojen TM, Houpt P. Glomus tumors of the hand in the Netherlands: analysis of 107 patients. Eur J Plast Surg 2000; 23(4): 224-6. [Crossref]

12. Frumuseanu B, Balanescu R, Ulici A, Golumbeanu M, Barbu M, Orita $\checkmark$, et al. A new case of lower extremity glomus tumor up-to date review and case report. J Med Life 20I2; 5(2): 2II.

13. Goldblum JR, Folpe AL, Weiss SW. Enzinger and Weiss's Soft tissue tumors. $6^{\text {th }}$ ed. Philadelphia: Elsevier-Saunders; 2014.

14. Calonje JE, Brenn T, Lazar AJ, McKee PH. Pathology of the Skin E-Book. 4th ed. Philadelphia: Saunders; 20II. p. 1746-8.

15. Folpe AL, Fanburg-Smith JC, Miettinen M, Weiss SW. Atypical and malignant glomus tumors: analysis of 52 cases, with a proposal for the reclassification of glomus tumors. Am J Surg Pathol 200I; 25(I): I-12. [Crossref] 